\title{
Analisis Faktor-faktor yang Mempengaruhi Kinera Pegawai dalam Pegawai Organisasi Sektor Publik
}

(Studi Pada Kantor Penyuluhan dan Konsultasi Perpajakan KP2KP Gunungsitoli)

\section{Victorinus Laoli}

STIE Pembangunan Nasional

vic.laoli@gmail.com

\begin{abstract}
Abstrak
The purpose of this research was examining the factors that affect the employee performance at the tax office in Semarang, Central One. The factors tested in this study were clear and measurable goals, incentives, motivation, remuneration, decentralization, and performance measurement systems for employee performance. This research was conducted by using questionnaires to all employees of KPP Semarang Central One. The data obtained was processed by using a regression that is part of the multiple regression. Number of questionnaires processed amounted to 40 questionnaires. The results of this study indicate that a clear and measurable goals, incentives, motivation, remuneration, decentralization is not related to employee performance. While performance measurement system affect employee performance.
\end{abstract}

Kata Kunci clear and measurable goals, incentives, motivation, remuneration, decentralization, and performance measurement systems

\section{PENDAHULUAN}

New Public Management/ NPM (Hood, 1991) merupakan paradigma baru yang muncul mulai tahun 1990-an yang juga sering disebut dengan nama lain misalnya Postbureaucratic Paradigm (Barzeley, 1992), dan Reinventing Government (Osborne dan Gaebler, 1992), tetapi secara umum disebut NPM karena berangkat dari gagasan Christopher Hood sebagai awal mula paradigma alternatif. Paradigma tersebut muncul akibat adanya kritikan keras yang ditujukan kepada organisasi sektor publik yang sering tidak produktif, tidak efisien, selalu rugi, rendah kualitas, miskin inovasi dan kreativitas. New Public Management berfokus pada manajemen sektor publik yang berorientasi pada kinerja, bukan berorientasi kebijakan. New Public Management pada awalnya lahir di negara- negara maju di Eropa dan Amerika. Namun, negara-negara berkembang juga sudah mulai menggunakan konsep ini, begitu juga dengan Indonesia.

Di Indonesia sendiri, pelaksanaan manajemen kinerja pada organisasi sektor publik sebenarnya sudah dimulai sejak tahun 1999 dengan dikeluarkannya Instruksi Presiden Nomor 7 Tahun 1999 tentang Akuntabilitas Kinerja Instansi Pemerintah. Penerapan New Public Management di Indonesia dapat dilihat dari penerapan beberapa karakteristik-karakteristiknya di dalam praktek-praktek yang tengah dijalankan oleh instansi- instansi pemerintahan di Indonesia.

Manajemen kinerja dapat didefinisikan sebagai daya upaya untuk meningkatkan kemampuan dan mendorong pegawai melalui berbagai cara agar bekerja dengan penuh semangat, efektif, efisien dan produktif, sesuai dengan proses kerja yang benar agar 
mencapai hasil kerja yang optimal. Menurut Heinrich (2002); Ittner dan Larcker (2001); Otley (1999); Kravchuk dan Schach (1996); dan Brickey et al. (1995) dalam verbeeten (2008) praktek manajemen kinerja meliputi tujuan yang akan dicapai, pengalokasian hak-hak keputusan, serta pengukuran dan pengevalusaian kinerja organisasi. Praktek manajemen kinerja ini dapat meningkatkan kinerja organisasi sektor publik.

Penetapan tujuan yang jelas dan terukur, pengukuran kinerja, dan pemberian insentif merupakan elemen penting dalam manajemen kinerja (Verbeeten, 2008; Kloot, 1999). Secara empiris, bukti-bukti mengenai pengaruh praktek manajemen kinerja organisasi sektor publik dalam skala besar masih terbatas (Van Helden, 2005; Merchant et al, 2003; Heinrich, 2002 dalam Verbeeten, 2008). Beberapa penelitian, dalam kaitannya dengan hubungan antara praktek manajemen kinerja dengan kinerja organisasi sektor publik antara lain adalah penelitian Verbeeten (2008), Indudewi (2009), Betsy (2010).

Dalam beberapa tahun belakangan ini,para pegawai sektor publik dari berbagai instansi, kementerian dan berbagai lembaga pemerintah lainnya sedang menikmati konsep remunerasi sebagai salah satu aspek dalam agenda reformasi birokrasi. Remunerasi tersebut ingin memperbaiki mekanisme penghasilan dan pendapatan seorang pegawai dari berbagai level, baik yang digolongan bawah yaitu I/a hingga paling tinggi golongan IV/e. Namun demikian, menurut perencanaan pemerintah, mekanisme ini tidak serta merta dapat diimplementasikan untuk seluruh pegawai pemerintah, karena harus menyesuaikan anggaran negara. Tujuan dari remunerasi adalah untuk perbaikan struktur dalam birokrasi dan meningkatkan kinerja pegawai pemerintahan (Adit,2011).

Instansi pajak merupakan salah satu organisasi sektor publik yang memiliki peran penting di setiap negara termasuk di Indonesia. Pajak mempunyai peranan yang sangat penting untuk kehidupan bernegara, karena pajak merupakan sumber pendapatan negara dan pajak akan digunakan dalam pembiayaan APBN. Pajak menurut Pasal 1 UU No.28 Tahun 2007 tentang Ketentuan umum dan tata cara perpajakan adalah "kontribusi wajib kepada negara yang terutang oleh orang pribadi atau badan yang bersifat memaksa berdasarkan Undang-Undang, dengan tidak mendapat timbal balik secara langsung dan digunakan untuk keperluan negara bagi sebesar-besarnya kemakmuran rakyat". Belakangan ini, perpajakan di Indonesia sering disorot karena prestasinya yang kurang maksimal dalam pemungutan pajak terhadap wajib pajak serta banyaknya kecurangan yang dilakukan oleh pegawai pajak dalam memanipulasi penerimaan pajak. Hal tersebut mengakibatkan target penerimaan pajak negara tidak pernah tercapai maksimal.

Penelitian ini memperluas penelitian yang dilakukan oleh Frank H.M. Verbeeten (2008) dengan menambahkan variabel remunerasi sebagai variabel independen dan juga menyesuaikannya untuk kondisi yang ada dalam praktik-praktik pengukuran kinerja di sektor publik Indonesia yaitu dengan menggunakan unit analisis yang lebih kecil yaitu KP2KP Gunungsitoli. Karena belum semua sektor publik di Indonesia menerapkan remunerasi. Penetapan tujuan yang jelas dan terukur, insentif, motivasi kerja pegawai, remunerasi, desentralisasi, serta sistem pengukuran kinerja merupakan variabel independen yang akan diteliti dalam penelitian ini. 


\section{LANDASAN TEORI}

\section{Konsep New Public Management}

Dalam perkembangannya, kelemahan dan ketertinggalan sektor publik dari sektor swasta memicu munculnya reformasi pengelolaan sektor publik dengan meninggalkan administrasi tradisional dan beralih ke New Public Management (NPM), yang memberi perhatian lebih besar terhadap pencapaian kinerja dan akuntabilitas, dengan mengadopsi teknik pengelolaan sektor swasta ke dalam sektor publik. Konsep New Public Management adalah salah satu reformasi manajemen sektor publik untuk menjawab anggapan yang menyatakan bahwa organisasi sektor publik tidak produktif, tidak efisien, selalu rugi, rendah kualitas, miskin inovasi dan kreatifitas, dan berbagai kritikan lainnya (Mahmudi, 2007). New Public Management beranggapan bahwa praktik manajemen sektor swasta lebih baik dibandingkan dengan praktik manajemen sektor publik. Oleh karena itu untuk memperbaiki kinerja sektor publik perlu diadopsi beberapa praktik dan teknik manajemen yang diterapkan di sektor swasta ke dalam sektor publik, seperti pengadopsian mekanisme pasar, kompetisi tender, dan privatisasi perusahaanperusahaan publik.

Walaupun penerapan NPM bervariasi, namun mempunyai tujuan yang sama yaitu memperbaiki efisiensi dan efektivitas, meningkatkan responsivitas, dan memperbaiki akuntabilitas manajerial. Pemilihan kebijakannya pun hampir sama, antara lain desentralisasi (devolved management), pergeseran dari pengendalian input menjadi pengukuran output dan outcome, spesifikasi kinerja yang lebih ketat, public service ethic, pemberian reward and punishment, dan meluasnya penggunaan mekanisme contracting-out (Hood, 1991; Boston et al.,1996 dalam Hughes and O’Neill, 2002; Mulgan, 1997).

NPM memberikan kontribusi positif dalam perbaikan kinerja melalui mekanisme pengukuran yang diorientasikan pada pengukuran ekonomi, efisiensi, dan efektivitas meskipun penerapannya tidak bebas dari kendala dan masalah. Masalah tersebut terutama berakar dari mental birokrat tradisional, pengetahuan dan ketrampilan yang tidak memadai, dan peraturan perundang-undangan yang tidak memberikan cukup peluang fleksibilitas pembuatan keputusan (Pecar, 2002).

\section{Sistem Pengendalian Manajemen dalam Organisasi Sektor Publik}

Pengendalian telah mengalami perkembangan definisi dari masa ke masa, yang cukup popular adalah pendapat Usury dan Hammer (1994:5) yang berpendapat bahwa "Controlling is management's systematic efforts to achieve objectives by comparing performances to plan and taking appropriate action to correct important differences" yang artinya pengendalian adalah sebuah usaha sistematik dari manajemen untuk mencapai tujuan dengan membandingkan kinerja dengan rencana awal kemudian melakukan langkah perbaikan terhadap perbedaan-perbedaan penting dari keduanya. Namun secara sederhana pengendalian dapat diartikan sebagai proses penyesuaian pergerakan organisasi dengan tujuannya.

Pentingnya sistem pengendalian manajemen dilaksanakan oleh organisasi karena sistem pengendalian manajemen mempengaruhi perilaku manusia. Sistem pengendalian yang baik berpengaruh pada cara manapun tujuannya; artinya tindakan-tindakan individu untuk meraih tujuan-tujuan pribadinya juga akan membantu dalam pencapaian tujuantujuan organisasi (Anthony \& govindarajan, 2002: 55). Dengan adanya suatu sistem itu pula berbagai ragam aktivitas dapat terkoordinir dan terarah menuju satu tujuan bersama. 
Proses pengendalian manajemen merupakan tahap-tahap yang harus dilalui untuk mewujudkan tujuan organisasi yang hendak dicapai. Proses pengendalian manajemen terdiri dari beberapa tahap, yaitu (Mahmudi, 2007): perumusan strategi, pembuatan program, penganggaran, implementasi, pelaporan kinerja, evaluasi kinerja dan umpan balik.

\section{Manajemen Berbasis Kinerja}

Manajemen berbasis kinerja dapat didefinisikan sebagai suatu proses penetapan tujuan, memilih strategi untuk mencapai tujuan tersebut, mengalokasikan wewenang keputusan, dan mengukur serta menghargai kinerja (Kravchuk dan Shack, 1996 dalam Betsy, 2010). Manajemen berbasis kinerja berkaitan dengan usaha, kegiatan atau program yang diprakarsai dan dilaksanakan oleh pimpinan organisasi (perusahaan) untuk merencanakan, mengarahkan dan mengendalikan prestasi karyawan (Ruky, 2002).

Secara teknis program ini memang harus dimulai dengan menetapkan tujuan dan sasaran yaitu "kinerja dalam bentuk apa dan yang seperti bagaimana" yang ingin dicapai. Karena yang menjadi obyek adalah kinerja manusia, maka bentuk yang paling umum tentunya adalah kinerja dalam bentuk kinerja produktivitas sumber daya manusia. Menurut Cascio (dikutip dari Ruky, 2002), sebuah program manajemen kinerja yang efektif hendaknya memenuhi syarat-syarat yakni relevance, sensitivity, reliability, acceptability dan practicalit.

\section{Motivasi Kerja}

Mangkunegara (2001) dalam Utami (2010) mendefenisikan motivasi sebagai suatu dorongan kebutuhan dalam diri pegawai atau karyawan yang perlu dipenuhi agar pegawai tersebut dapat menyesuaikan diri terhadap lingkungannya untuk mencapai tujuan yang hendak dicapai seorang pegawai dalam bekerja. Sedangkan menurut Riyadi (1998) dalam Wijayanti dan Solichatun (2005:184), motivasi didefinisikan sebagai derajat sampai dimana seorang individu (manajer/atasan) ingin berusaha dan untuk melaksanakan suatu tugas atau pekerjaan dengan baik. Partisipasi penyusunan anggaran mungkin akan efektif dalam kondisi karyawan yang mempunyai motivasi yang tinggi, begitu pula sebaliknya.

Motivasi seringkali dikatakan menjadi kunci kinerja kerja. Kinerja dapat ditingkatkan dengan motivasi kerja yang tinggi, pengetahuan dan keahlian dalam melakukan tugas dan persepsi peran positif yang dimiliki seseorang. Oleh karena itu memotivasi Sumber Daya Manusia yang terlingkup dalam suatu organisasi lebih banyak berhubungan dengan pemeliharaan kultur organisasi untuk mendorong prestasi kerja.

\section{Penelitian Terdahulu}

Frank H. M. Verbeeten dalam penelitiannya yang berjudul "Performance Management Practices in Public Sector Organisation, impact on performance" meneliti pengaruh tujuan yang jelas dan terukur, insentif, desentralisasi, pengukuran kinerja, sektor dan ukuran organisasi terhadap kinerja sektor publik. Disimpulkan bahwa tujuan yang jelas dan terukur dapat meningfkatkan kinerja baik secara kualitas maupun secara kuantitas. Sedangkan insentif dapat meningkatkan kuantitas kinerja, namun tidak berpengaruh terhadapa kinerja secara kualitatif.

Penelitian oleh Josephine Betsy berjudul "Faktor-faktor yang Mempengaruhi Kinerja Organisasi Sektor Publik (Studi pada Pemerintah Daerah Kabupaten Demak) 
mendapatkan hasil tujuan yang jelas dan terukur berpengaruh terhadap kinerja pemerintah daerah kabupaten Demak. Insentif tidak berpengaruh terhadap kinerja karena insentif pada pemerintah daerah kabupaten Demak masih dihitung berdasarkan absensi bukan terhadap kinerjanya. Motivasi kerja juga tidak berpengaruh karena minimnya kesempatan untuk naik jabatan ke jenjang lebih tinggi.

\section{Kerangka Konsep}

\begin{tabular}{|l|}
\hline Tujuan yang jelas dan terukur \\
\hline Insentif \\
\hline \hline Motivasi Kerja \\
\hline \hline Remunerasi \\
\hline Desentralisasi \\
\hline Sistem Pengukuran Kinerja \\
\hline
\end{tabular}

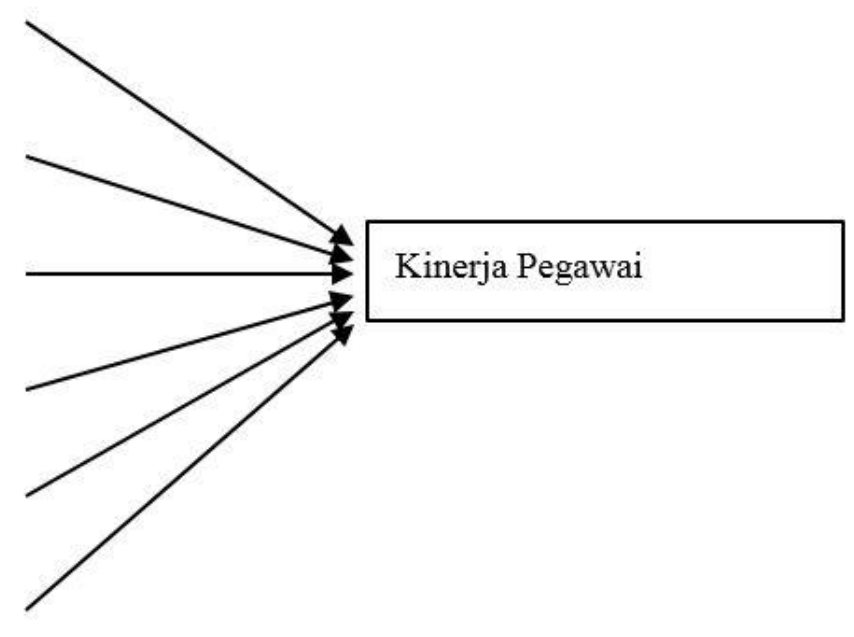

\section{Hipotesis}

Hipotesis merupakan jawaban yang sifatnya sementara berdasarkan rumusan masalah yang kebenarannya akan diuji dalam pengujian hipotesis (Sugiyono 2003:306). Berdasarkan perumusan masalah yang ada, maka hipotesis penelitian dapat dirumuskan sebagai berikut :

$\mathrm{H} 1$ = ada pengaruh tujuan yang jelas dan terukur terhadap kinerja.

$\mathrm{H} 2$ = ada pengaruh insentif terhadap kinerja.

$\mathrm{H} 3$ = ada pengaruh motivasi kerja terhadap kinerja.

$\mathrm{H} 4$ = ada pengaruh remunerasi terhadap kinerja.

$\mathrm{H} 5$ = ada pengaruh desentralisasi terhadap kinerja.

$\mathrm{HO}=$ tidak ada pengaruh tujuan yang jelas dan terukur, insentif, motivasi kerja, remunerasi, dan desentralisasi terhadap kinerja.

\section{METODOLOGI PENELITIAN}

Data pengujian adalah data primer. Data primer ini dikumpulkan dengan metode kuesioner. Jenis data didalam penelitian ini adalah data subyek yaitu berupa opini dan pengalaman dari responden dengan mengacu pada kriteria pengukuran variabel yang digunakan yaitu: tujuan yang jelas dan terukur, insentif, motivasi kerja, remunerasi, desentralisasi, dan sistem pengukuran kinerja. Respondennya adalah semua pegawai KP2KP Gunungsitoli.

Prosedur pengumpulan data menggunakan pengumpulan data primer, yaitu kuesioner. Kuesioner yang telah terstruktur dibagikan secara langsung kepada responden untuk diisi. Kuesioner dibagi menjadi tujuh bagian. Bagian pertama menanyakan mengenai demografi responden. Bagian kedua berisi pertanyaan mengenai tujuan yang jelas dan terukur. Bagian ketiga berisi pertanyaan mengenai insentif. Bagian 
keempat berisi pertanyaan mengenai motivasi kerja. Bagian kelima berisi pertanyaan mengenai remunerasi. Bagian keenam mengenai desentralisasi. Bagian tujuh berisi pertanyaan mengenai sistem pengukuran kinerja. Dan bagian kedelapan berisi pertanyaan mengenai kinerja pegawai.

Statistik deskriptif digunakan untuk mendeskripsikan variabel-variabel dalam penelitian ini. Alat analisis yang digunakan adalah rata-rata (mean), standar deviasi, maksimum dan minimum (Ghozali, 2006) . Statistik deskriptif menyajikan ukuranukuran numerik yang sangat penting bagi data sampel. Uji statistik deskriptif tersebut dilakukan dengan program SPSS 21. Uji kualitas data yang dihasilkan dari penggunaan instrumen penelitian dapat dievaluasi melalui uji validitas dan uji reliabilitas.

Untuk menentukan ketepatan model regresi perlu dilakukan pengujian atas beberapa asumsi klasik (Multikolinearitas, Heterokedastisitas, dan Normalitas) yang mendasari model regresi dengan menggunakan aplikasi program komputer atau software Statistical Product and Service Solution (SPSS) for Windows.

Metode statistik yang digunakan untuk menguji hipotesis adalah regresi berganda (multiple regression) dengan alasan bahwa alat ini dapat digunakan sebagai model prediksi terhadap variabel dependen dengan beberapa variabel independen. Hasil analisis regresi adalah berupa koefisien untuk masing-masing variabel independen.

Model regresi yang digunakan untuk menguji hipotesis adalah sebagai berikut:

$\mathrm{Y}=\mathrm{a}+\mathrm{b} 1 \mathrm{X} 1+\mathrm{b} 2 \mathrm{X} 2+\mathrm{b3X3}+\mathrm{b4X} 4+\mathrm{b5X5}+\mathrm{b} 6 \mathrm{X6}+\mathrm{e}$

\section{HASIL PENELITIAN}

\section{Hasil Pengujian Statistik Deskriptif}

Statistik deskriptif digunakan untuk memberikan gambaran mengenai variablevariable penelitian (kepemimpinan, komitmen organisasi, lingkungan kerja, kepuasan kerja, dan kinerja pegawai) yang menunjukkan rata-rata dan standar deviasi, disajikan dalam tabel di bawah ini

Tabel 1.1

Statistik Deskriptif

\begin{tabular}{|l|c|c|c|c|}
\hline \multicolumn{1}{|c|}{ Variabel } & Minimum & Maximum & $\begin{array}{c}\text { Rata- } \\
\text { rata }\end{array}$ & $\begin{array}{c}\text { Standar } \\
\text { Deviasi }\end{array}$ \\
\hline $\begin{array}{l}\text { Tujuan yang } \\
\text { jelas dan terukur }\end{array}$ & 3,154 & 4,692 & 3,881 & 0,329 \\
\hline Insentif & 3,375 & 5,000 & 4,006 & 0,366 \\
\hline Motivasi Kerja & 3,3 & 5,0 & 3,921 & 0,343 \\
\hline Remunerasi & 3,333 & 4,867 & 3,900 & 0,335 \\
\hline Desentralisasi & 3,247 & 4,587 & 3,870 & 0,323 \\
\hline $\begin{array}{l}\text { Sistem } \\
\text { Pengukuran }\end{array}$ & 3,273 & 5,000 & 4,001 & 0,302 \\
\hline
\end{tabular}

Sumber : Data Primer diolah 2019

Berdasarkan tabel statistik deskriptif di atas, menunjukkan bahwa variabel tujuan yang jelas dan terukur menunjukkan rata-rata sebesar 3,881, insentif 4,006, motivasi 
kerja 3,921, remunerasi 3,900, desentralisasi 3,870 dan system pengukuran kinerja 4,001. Sedangkan nilai standar deviasi berada di bawah nilai 1 yang berarti data memiliki nilai penyimpangan masih dalam batas toleransi (Yunianto, 2006).

\section{Pembahasan}

Berdasarkan pengujian instrument yang telah dilakukan maka dapat disimpulkan bahwa seluruh item pada semua variabel dinyatakan valid dan reliabel. Untuk menguji apakah dalam model regresi, variabel independen dan dependen keduanya mempunyai distribusi normal atau tidak, dilakukan uji normalitas dengan Kolmogorov Smirnov (dilampiran) diperoleh nilai Asym. sig. sebesar 0,083. Hasil ini memiliki nilai Asym. sig. lebih besar dari 0,05, maka dapat disimpulkan data penelitian berdistribusi normal.

Untuk mengetahui apakah dalam model regresi ditemukan korelasi antar variable bebas dilakukan uji multikolinearitas. Hasil uji multikolinearitas menunjukkan bahwa masing-masing variabel bebas mempunyai nilai Tolerance lebih besar dari 0,1 dan nilai VIF kurang dari 10 sehingga dapat disimpulkan tidak terjadi gejala multikolinearitas.

Untuk menguji apakah dalam model regresi terjadi ketidaksamaan variance dari residual satu pengamatan ke pengamatan yang lain tetap. Uji heteroskedastisitas menggunakan uji Glejser yaitu meregresikan nilai absolute residual terhadap variabel independen, jika diperoleh nilai signifikansi lebih besar dari 0,05 maka tidak terjadi masalah heteroskedastisitas. Selanjutnya hasil uji heteroskedastisitas untuk masingmasing variabel menunjukkan nilai signifikansi lebih besar dari 0,05, sehingga dapat disimpulkan tidak terjadi gejala heteroskedastisitas.

\section{Analisis Regresi Linear Berganda}

Untuk menguji hipotesis yang diajukan dalam penelitian terdahulu dilakukan analisis regresi linear berganda. Berdasarkan hasil olah data sebagaimana terlampir, maka dapat disusun fungsi persamaan regresi sebagai berikut:

$$
\mathrm{Y}=0,971+0,193 \mathrm{X} 1+0,208 \mathrm{X} 2+0,269 \mathrm{X} 3+0,255 \mathrm{X} 4+0,196 \mathrm{X} 5+0,234 \mathrm{X} 6+\mathrm{e}
$$

Persamaan di atas menunjukkan bahwa variabel tujuan yang jelas dan terukur menunjukkan $(0,193)$, insentif $(0,208)$, motivasi kerja $(0,269)$, remunerasi $(0,255)$, desentralisasi $(0,196)$ dan sistem pengukuran kinerja $(0,234)$. Berarti variabel tujuan yang jelas dan terukur, insentif, motivasi kerja, remunerasi, desentralisasi dan sistem pengukuran kinerja berpengaruh positif dan signifikan terhadap kinerja pegawai.

\section{KESIMPULAN DAN SARAN}

\section{A. KESIMPULAN}

Berdasarkan hasil olah data dengan alat SPSS 21.0 diperoleh nilai F hitung sebesar 51,556. Artinya model yang digunakan dalam penelitian ini adalah tepat (fit).

Hasil uji hipotesis (uji t) menunjukkan bahwa : tujuan yang jelas dan terukur, insentif, motivasi kerja, remunerasi, desentralisasi, dan sistem pengukuran kinerja secara parsial maupun simultan berpengaruh signifikan terhadap kinerja pada Kantor Penyuluhan Dan Konsultasi Perpajakan KP2KP Gunungsitoli.

Berdasarkan penelitian yang telah dilakukan, maka dapat terlihat bahwa secara parsial semua variabel independen berpengaruh terhadap variabel dependen secara positif, artinya jika nilai variabel independen naik, maka nilai variabel dependen juga akan naik. 


\section{B. SARAN}

Variabel bebas yang diteliti hanya terbatas pada 6 variabel di atas, selanjutnya untuk peneliti yang akan datang sebaiknya menambah variabel lain misalnya variabel lingkungan kerja, variabel budaya organisasi, variabel etos kerja, variabel komunikasi, variabel komitmen organisasi dan lainnya.

Dalam mengisi kuesioner responden tidak dipandu oleh peneliti, sehingga memungkinkan hasilnya kurang mencerminkan keadaan yang sesungguhnya.

Sampel dalam penelitian hanya satu instansi saja, yaitu Kantor Penyuluhan Dan Konsultasi Perpajakan KP2KP Gunungsitoli, sehingga hasil penelitian tidak bisa digeneralisasi.

Pimpinan Kantor Penyuluhan Dan Konsultasi Perpajakan KP2KP Gunungsitoli perlu memperhatikan desentralisasi dan system pengukuran kinerja para pegawai agar dapat memberikan remunerasi yang sesuai dengan kapasitas dan kapabilitas masing-masing pegawai.

\section{DAFTAR PUSTAKA}

Allen, N.J. \& Meyer, J.P. 1990. "The Measurement and Antecedents of Affective, Continuance and Normative Commitment to The Organization : A Metaanalysis of Antecedents, Correlates, and Consequences", Journal of Occupational Psychology, Vol. 63, p. 1-18

Barzelay, M. (2005). Origins of the new public management: an international view from public administration/political science. In New Public Management (pp. 27-45). Routledge.

Dawal, Siti Zawiah \& Zahari Taha. 2006. "The Effect of Job and Environmental Factors On Job Satisfaction in Automotive Industries", International Journal of Occupational Safety and Ergonomics (JOSE), Vol. 12 No.3, p. 267-280

Yousef, D.A., 2000. Organizational Commitment: A Mediator of Relationship of Leadership Behavior with Job Satisfaction and Performance in Non-Western Country. Journal of Managerial Psychology. Vol 5 No.1, p. 6-28

Hameed, 2014. Impact of Compensation on Employee Performance (Empirical Evidence from Banking Sector Pakistan. International Journal of Business and Social Science Vol. 5 No. 2

Henrich, J."Decision-making, cultural transmission and adaptation in economic anthropology." In Theory in Economic Anthropology, edited by Jean Ensminger, 251-295. Walnut Creek, CA: AltaMira Press, 2002.

Hood, C. (1991). A public management for all seasons?. Public administration, 69(1), 3 19.

Ittner, C. D., \& Larcker, D. F. (2001). Assessing empirical research in managerial accounting: a value-based management perspective. Journal of accounting and economics, 32(1-3), 349-410. 
Kravchuck, R.S. and R.W. Schack, (1996), "Designing effective performance measurement systems under the government performance and results act of 1993”,

Public Administration Review, Vol. 56 No.4, PP. 348-358

Osborne, D. and Gaebler, T. 1992. Reinventing Government. New York, NY

Osibiya, 2015. "The Impact of Leadership Style on Employee's Performance in an Organization". Public Policy and Administration Research www.iiste.org diakses tanggal 10 Maret 2019

Otley, D. (1999). Performance management: a framework for management control systems research. Management accounting research, 10(4), 363-382.

Qureshi, 2015. An Empirical Analysis of The Impact Compensation on Job Performance and Work Family Conflict in The Kingdom Of Saudi Arabia. eujournal.org > Home > Vol 11, No 4..arab /viewFile/5148/5037 diakses tanggal 12 Februari 2019

Kuncoro, Mudrajat 2003. Metode Riset Untuk Bisnis dan Ekonomi. Penerbit Erlangga, Jakarta Lamb, Charles W, Hair, Joseph F, dan McDaniel, Carl 2001. Pemasaran . Buku satu, Penerbit Salemba Empat, Jakarta

Sugiyono, 2003. Metode penelitian Bisnis. Cetakan kesembilan Bandung, CV. Alfabeta.

Sumarwan,Ujang. 2003. Perilaku Konsumen. Cetakan Pertama, Penerbit Ghalia Indonesia, Jakarta

Supranto, 2000, Prosedur Penelitian, BPFE, Yogyakarta

Swastha, Basu 2001. Azas-azas Marketing. Penerbit Liberty, Yogyakarta

Tjiptono, Fandy 2005. Pemasaran Jasa. Edisi Pertama, Penerbit Bayumedia Publishing, Malang

Verbeeten, Frank H.M. (2008). "Performance management Practices in Public Sector organizations: Impact on Performance”. Accounting, Auditing \& Accountability Journal, Vol.21 No. 3, pp.427-454 